\title{
An operational monitoring tool facilitating the transformation of urban brownfields into sustainable neighborhood
}

Martine Laprise ${ }^{1, *}$, Sophie Lufkin ${ }^{1}$, Emmanuel Rey ${ }^{1}$

${ }^{1}$ Laboratory of Architecture and Sustainable Technologies (LAST), Institute of Architecture and the City (IA), School of Architecture, Civil and Environmental engineering (ENAC), Ecole polytechnique fédérale de Lausanne (EPFL), BP 2225/Station 16, CH-1015 Lausanne, Switzerland

* Corresponding author. EPFL, ENAC, IA, LAST, LE 1112/Station 16, CH-1015 Lausanne, Switzerland Tel.: +4121693 0875 Fax: +41 2169308 85. E-mail address: martine.laprise@epfl.ch (M. Laprise)

Abstract(150-250 words)

The regeneration of urban brownfields is a relevant strategy to limit the sprawling of post-industrial European cities. However, the integration of sustainability issues in urban brownfield regeneration projects is not a spontaneous process, remaining in most cases partial or superficial. Achieving the goals of sustainable development requires high global quality objectives, integrated into the project dynamics, and a continuous monitoring of environmental, social, and economic indicators, adapted to the specificities of brownfields. Following these considerations, an operational monitoring tool facilitating the transformation of urban brownfields into sustainable neighborhoods was created. This paper presents and discusses the verification stage of the tool, divided into two complementary tests: 1) test-applications on three case studies in Belgium, France and Switzerland and 2) interactions with the involved stakeholders.

First, we describe the functioning of the tool. Then, we present the test-applications results, focusing on the Val Benoit project in Liège (Belgium). They are followed by the interactions with the stakeholders that took the form of roundtable discussions. Finally, we discuss the performance of the tool looking at its potential added-value. It reveals that an adapted operational monitoring tool can facilitate sustainability assessment, reporting, decisionmaking and multidisciplinary collaboration. Globally speaking, the integration of monitoring practices appears not only feasible, but also realistic and desired.

Keywords: (6) Monitoring tool; Brownfield regeneration; Sustainable neighborhood; Sustainability assessment, Indicator system, Decision-making.

\section{Introduction}

\subsection{Urban Brownfield Regeneration Projects and sustainability issues}

It is now generally acknowledged that most European countries are confronted with the problem of urban sprawl and are coping with its negative impacts. There is no need to dwell on the fact that excessive and disorganized consumption of land, resulting from the sprawling of post-industrial cities, causes environmental damages, is economically unviable and creates social disparities [1,2]. To address these contradictions with the concept of sustainable development, a consensus has emerged in order to promote densification within already built areas [3]. Referring to the compact and polycentric city model [4,5], the goal is to increase density and improve accessibility in urban areas while reducing spatial dissociation of functions. Various densification 
strategies comply with the compact and polycentric city model: urban renewal, vertical extension of buildings, construction on vacant parcels of urban land, or urban brownfields regeneration. This paper focuses on the latter.

In the early 2000s, the Cabernet Network has offered the most commonly accepted characterization of brownfield sites [6]. It puts emphasis on the fact that brownfields "[...] require intervention to bring them back to beneficial use". In today's context looking towards the sustainable city, "beneficial use" implies that a brownfield regeneration project includes environmental, social and economic considerations. The transformation of brownfields into sustainable neighborhoods has the potential to meet these considerations. Indeed, beyond the densification of the existing built fabric, this type of regeneration projects can contribute to the revitalization of some portions of cities and metropolitan areas. In this sense, because of their size between the urban and the architectural scale, these projects can improve mobility impacts and foster mixed-used developments $[7,8]$. In addition, numerous authors argue that urban brownfield regeneration projects (UBRP) can be beneficial to the environment (site remediation, ecosystem strengthening, etc.) $[9,10]$, the society (health improvements, social inclusion, architectural heritage preservation, etc.) $[8,11,12]$ and the economy (job creation, additional tax revenue, etc.) $[13,14]$.

However, even though focusing on urban brownfields regeneration is a sustainable land take solution, their transformation into sustainable neighborhoods is not automatic [15]. As a matter of fact, despite their significant potential, the holistic integration of environmental, social and economic objectives is often partial or superficial in this type of operations $[16,17]$. This difficulty in integrating sustainability issues in the project dynamics is explained by three interconnected factors. First, the complexity of the site: brownfields are complicated sites covering an intermediate scale (the neighborhood), often disconnected from their context, sometimes contaminated, with a building legacy of variable quality, and suffering from a poor image. Second, the complexity of the regeneration project process: it involves multiple stakeholders and lasts often over a decade. On that basis, chances are that the different stakeholders will change during the project, which makes it difficult to keep to the end objectives that were set at the beginning. Finally, the complexity of the concept of sustainability itself: it asks for the simultaneous consideration of a multitude of parameters that are not necessarily compatible. In consequence, the integration of sustainability in UBRP is not a spontaneous process and goes far beyond the limits of intuition.

\subsection{Need for a tailor-made operational monitoring tool}

To handle the overall complexity of the transformation of urban brownfields into sustainable neighborhoods, it is essential to act on the basis of sound information and to put a system in place to collect it as appropriate [18]. To this end, it appears essential to assess equally and concurrently environmental, social and economic criteria. Today, a "fourth pillar" enhances the sustainability concept. This new pillar, often involving governance considerations, refers to all means deployed to identify and integrate sustainability objectives in a project process in order to increase their success. It serves as a link between short and long-term preoccupation as well as between local and global scale $[19,20]$. To be accurate, the assessment must take into account the 
specificities of UBRP [21] as well as the national/regional context [20]. The assessment results should bring insightful elements to support decisions in a way that allows an iterative setting of sustainability objectives. To do so, a balance between exhaustive and concise information is needed, provided by a multidisciplinary approach [22]. Besides, to pursue sustainability objectives throughout the operation, regular assessments must be an integral part of the project dynamics [23]. In sum, an operational monitoring tool is required. To comply with the above considerations, the tool should satisfy three general requirements [24]:

(I) a search for global quality;

(II) an adequacy with the specificities of UBRP;

(III) an integration into the project dynamics.

Recent researches fostering the regeneration of brownfields look at mitigating their impact on the built environment and focus mostly either on soil remediation or on-site prioritization at a territorial level. Most cited examples of these works are the HOMBRE and the TIMBRE projects $[25,26]$. A state of the art [27] has reported few frameworks and sustainability indicators systems adapted to brownfield regeneration projects into new neighborhoods [24,28-31]. In all cases, this study shows that these approaches do not entirely fulfill the three general requirements. As they are dissociated from the overall project dynamics, they cannot be applied on a regular basis or do not address all the phases of a project.

In reaction to that, a new operational monitoring tool was created [32]. Entitled SIPRIUS+, this tool combines two existing approaches: SIPRIUS, a sustainability indicator system adapted to issues raised by brownfield regeneration [27], and OKpilot, a user-friendly web-based monitoring software designed to check and manage compliance with different frameworks and checklists [33]. The originality of SIPRIUS+ thus originates from the hybridization of existing know-how coming from different fields, namely the built environment (SIPRIUS) and the business management (OKpilot). Hybridization offers the possibility of combining different techniques to compensate for the complexity of decision-making in a world where information is varied and sometimes contradictory [34]. This new generation hybrid tool is therefore part of transdisciplinary research [35].

A series of adaption was required in order to bring the two know-hows together and to make a fully operational monitoring tool. It consists mainly, on one side, at making updates, adjustments, and additions to the indicator system and, on the other side, at adapting the software to assess and display the sustainability indicators according to the logic of SIPRIUS. The complete methodology behind this work and the results were previously presented [32].

\subsection{Objectives}

With an operational monitoring tool in hand, the objective of this paper is to present and discuss the results of the verification process of SIPRIUS+ on ongoing cases studies representative of UBRP. Two different forms of tests were undertaken to check the compliance of the tool with the three general requirements. To assist us in this verification phase, we have divided the three requirements into eight attributes that the tool must meet: 
(I) Search for global quality:

1. The tool must assess the three pillars of sustainability;

2. The tool must assess the "fourth pillar" of sustainability;

(II) Adequacy with the specificities of UBRP:

3. The tool must be specific to urban brownfields issues;

4. The tool must be specific to the process of the regeneration project, in particular, its multidisciplinary aspect;

(III) Integration into the project dynamics:

5. The tool must include ex ante assessment and follow up;

6. The tool must include in itinere assessment and follow up;

7. The tool must include ex post assessment and follow up;

8. The tool must promote continuous improvement of the UBRP.

In the first verification stage, we did test-applications on three cases studies in Belgium, France, and Switzerland to validate the functioning and robustness of the monitoring tool. In the complementary second verification stage, we interacted with the stakeholders involved in each case study. These interactions consist mainly of roundtables challenging the tool and its results with the future end users' point of view and the reality of the practice. Both verification stages results are analyzed against the eight attributes.

The following chapter explains briefly the functioning of the operational monitoring tool SIPRIUS+. Chapter 3 presents the results of the test-applications, focusing on the Val Benoit case study located in Liège (Belgium). Chapter 4 presents the interactions with stakeholders and their perception of the tool. Chapter 5 discusses the results of both verification stages. Essentially, it demonstrates the relevance of the operational monitoring tool in terms of sustainability objectives, its applicability within concrete UBRP, its potential added-value to the professional practice, and underlines the obstacles to overcome prior to a real-world implementation.

\section{Functioning of the operational monitoring tool}

As previously mentioned, the monitoring tool SIPRIUS+ is a hybrid between an indicator system and a monitoring software. The indicator system SIPRIUS is the background of SIPRIUS+, supported by the monitoring software OKpilot (see Figure 1). This combination makes the sustainability follow-up of a UBRP operational as it can be done easily, on a regular basis and in a structured way. The operational monitoring tool SIPRIUS+ is designed to allow collaboration between different professionals involved in the project assessment. Tailor-made assessment results should be easy to interpret and simple to communicate. We present here the functioning of SIPRIUS+ through the features of the indicator system and the monitoring software embedded in the tool. 


\section{SIPRIUS +}

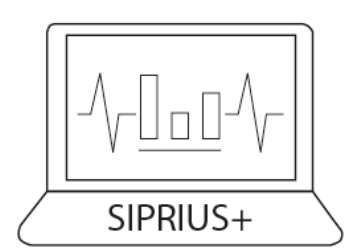

Checklists BE / CH / FR

criteria, indicators and reference values
Assesment steps

reference sources

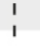

i

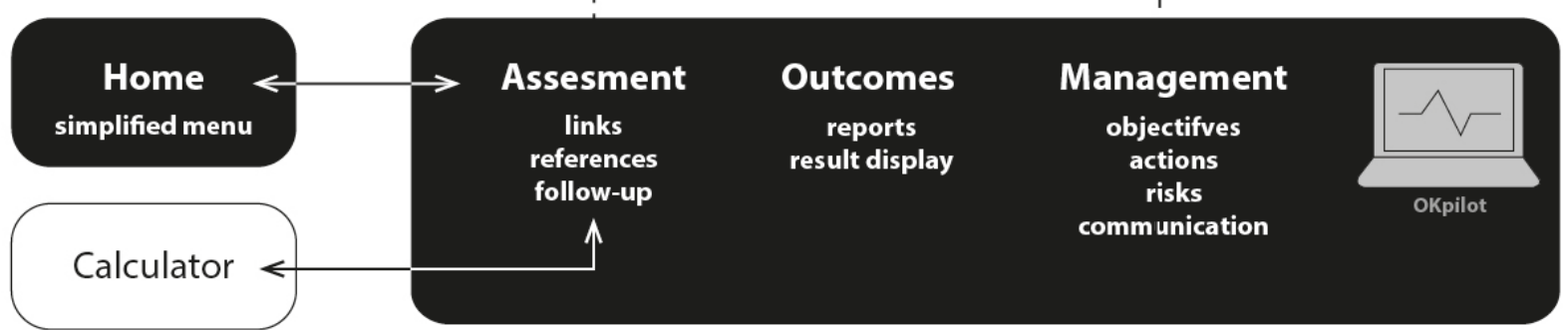

Figure 1 Schematic representation of the structure of SIPRIUS+ hybridizing an indicator system (SIPRIUS) and a monitoring software (OKpilot).

\subsection{Features of the indicator system}

The indicator system of SIPRIUS+ is designed to measure several quantitative and qualitative sustainability indicators - covering environmental, socio-cultural, economic, and governance aspects - and to follow their evolution through the project process, from ex ante to ex post assessment. They are grouped under three categories of criteria: Context criteria (aspects of the projects which have an impact on the context or aspects of the context which have an impact on the project); Project criteria (aspects of the project which have mainly an impact in the limits of the project); Governance criteria (aspects in relation with the management and the process of the project). It addresses specifically the sustainability issues raised by urban brownfield regeneration projects. In this sense, it explicitly fosters the development of new sustainable neighborhoods on these complex sites [27].

Table 1, Table 2, and Table 3 respectively show a summary list of the context, project, and governance criteria and indicators. Within these three lists, we identify the indicators that have been updated and the ones that have been added from the original version of SIPRIUS [27]. 
Table 1 Summary list of context criteria and indicators. Indicators marked by an asterisk (*) have been updated from the original version. Criteria and indicators marked by a plus sign (+) have been added to the list.

\begin{tabular}{|c|c|c|c|c|}
\hline & \multicolumn{2}{|c|}{ Criteria } & \multicolumn{2}{|c|}{ Indicator } \\
\hline & Code & Title & Code & Title \\
\hline \multirow{9}{*}{ 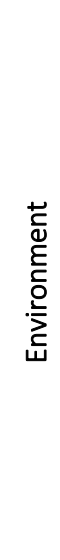 } & $\mathrm{C} 1$ & Mobility & C1.1 & Quality of service in public transport \\
\hline & & & $\mathrm{C} 1.2$ & Number of parking spaces \\
\hline & & & * $\quad \mathrm{C} 1.3$ & Tying status with soft mobility networks \\
\hline & & & $+\mathrm{C} 1.4$ & Company mobility plan \\
\hline & $\mathrm{C} 2$ & Air pollution & * C2.1 & Average annual emissions of $\mathrm{NO}_{2}$ \\
\hline & & & $* \quad \mathrm{C} 2.2$ & Global warming potential (GWP) \\
\hline & & - & $-\quad C 2.3$ & Acidification potential (AP) \\
\hline & C3 & Noise pollution & C3.1 & Average emissions of noise - day \\
\hline & & & C3.2 & Average emissions of noise - night \\
\hline+ & C4 & Light pollution & C4.1 & Degree of prevention of light emissions \\
\hline \multirow{10}{*}{ 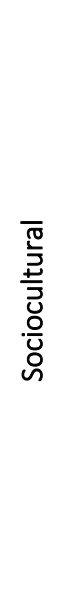 } & $\mathrm{C} 5$ & Proximity of school facilities & C5.1 & Average distance to a nursery \\
\hline & & & C5.2 & Average distance to a kindergarten \\
\hline & & & C5.3 & Average distance to an elementary school \\
\hline & & & C5.4 & Average distance to a junior high/ middle school \\
\hline & & & C5.5 & Average distance to a high school \\
\hline & C6 & Proximity of commercial facilities & C6.1 & Average distance to a commercial zone \\
\hline & $\mathrm{C} 7$ & Proximity of recreational facilities & C7.1 & Average distance to a public park \\
\hline & & & C7.2 & Average distance to a recreational green/ natural area \\
\hline & & & C7.3 & Average distance to a cultural center \\
\hline & & & C7.4 & Average distance to a sport center \\
\hline \multirow{3}{*}{$\begin{array}{l}\text { 을 } \\
\text { 음 } \\
\text { 엄 }\end{array}$} & $\mathrm{C} 8$ & Population & C8.1 & Net population density \\
\hline & C9 & Job & C9.1 & Net employment density \\
\hline & C10 & Local economy & C10.1 & Proportion of work carried out by local companies \\
\hline
\end{tabular}

Table 2 Summary list of project criteria and indicators. Indicators marked by an asterisk (*) have been updated from the original version. Criteria and indicators marked by a plus sign (+) have been added to the list.

\begin{tabular}{|c|c|c|c|c|c|}
\hline & \multicolumn{3}{|c|}{ Criteria } & \multicolumn{2}{|c|}{ Indicator } \\
\hline & Code & Title & & Code & Title \\
\hline \multirow{6}{*}{ 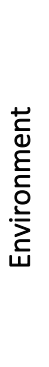 } & P1 & Land & & P1.1 & Land use coefficient \\
\hline & $\mathrm{P} 2$ & Energy & $*$ & P2.1 & $\begin{array}{l}\text { Non-renewable primary energy for construction, renovation } \\
\text { and demolition of buildings }\end{array}$ \\
\hline & & & $*$ & P2.2 & Non-renewable energy for buildings in operation \\
\hline & P3 & Water & & P3.1 & Infiltration surface and stormwater use \\
\hline & P4 & Biodiversity & & P4.1 & Green surfaces \\
\hline & & & + & P4.2 & Degree of ecosystem considerations \\
\hline
\end{tabular}




\begin{tabular}{|c|c|c|c|c|c|}
\hline \multirow{11}{*}{ 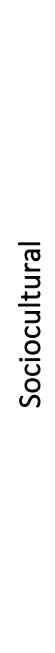 } & P5 & Well-being & $*$ & P5.1 & Annual hours of overheating \\
\hline & & & & P5.2 & Interior noise level \\
\hline & & & $*$ & P5.3 & Spatial daylight autonomy (sDA) \\
\hline & & & & P5.4 & Degree of electrosmog \\
\hline & & & & P5.5 & Degree of individualization of housing \\
\hline & & & & P5.6 & Quality of outdoor spaces \\
\hline & P6 & Security & & P6.1 & Degree of security \\
\hline & P7 & Heritage & & P7.1 & Degree of enhancement of existing heritage \\
\hline & P8 & Diversity & & P8.1 & Degree of functional mix \\
\hline & & & & P8.2 & Potential of social diversity \\
\hline & & & & P8.3 & Degree of universal access \\
\hline \multirow{6}{*}{ 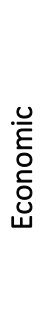 } & P9 & Direct costs & & P9.1 & Investment costs \\
\hline & & & & P9.2 & Gross rental yield \\
\hline & P10 & Indirect costs & & P10.1 & Annual operating costs \\
\hline & & & + & P10.2 & Level of occupancy \\
\hline & P11 & External costs & - & P11.1 & External costs \\
\hline & P12 & Flexibility & & P12.1 & Degree of buildings flexibility \\
\hline
\end{tabular}

Table 3 Summary list of governance criteria and indicators. Criteria and indicators marked by a plus sign (+) have been added to the list.

\begin{tabular}{|c|c|c|c|c|}
\hline & \multicolumn{2}{|c|}{ Criteria } & \multicolumn{2}{|c|}{ Indicator } \\
\hline & Code & Title & Code & Title \\
\hline \multirow{7}{*}{ 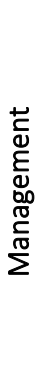 } & $+\mathrm{G} 1$ & Remediation & G1.1 & Logic of the project footprint \\
\hline & & & G1.2 & Degree of site remediation \\
\hline & & & G1.3 & Degree of residual contamination \\
\hline & $+\mathrm{G} 2$ & Temporary use & $\mathrm{G} 2.1$ & Temporary use Initiatives \\
\hline & $+\mathrm{G} 3$ & Construction site & G3.1 & Management of construction wastes \\
\hline & & & G3.2 & Management of construction disturbances \\
\hline & $+\mathrm{G} 4$ & Commissioning & G4.1 & Commissioning plan for buildings \\
\hline \multirow{4}{*}{$\begin{array}{l}\text { ֻั } \\
\text { ญू } \\
\text { 은 }\end{array}$} & $+\mathrm{G} 5$ & Participation & G5.1 & Degree of population participation \\
\hline & $+\mathrm{G} 6$ & Collaboration & G6.1 & Degree of professional collaboration \\
\hline & $+\mathrm{G} 7$ & Information access & G7.1 & Degree of information access \\
\hline & $+\mathrm{G} 8$ & Evaluation & G8.1 & Degree of integration of an evaluation process \\
\hline
\end{tabular}

These 3 summary lists are catalogs in which practitioners can choose the appropriate indicators to facilitate the transformation of an urban brownfield into a new sustainable neighborhood. The 3 lists are adapted to the French, Belgium and Swiss contexts and can be selected as a checklist in the monitoring software according to the location of the project. 
To measure and compare each indicator, four reference values are attributed: the Limit Value (VL), the Average Value (VA), the Target Value (VT) and the Best Practice Value (VB). Each indicator has its own datasheet containing all the relevant information to perform the assessment (description, evaluation method, measurement unit, reference values, references). As examples, Table 4 shows the datasheet of a qualitative context indicator (C4.1 Degree of prevention of light emission) and Table 5 shows the datasheet of a quantitative project indicator (P5.3 Spatial daylight autonomy - sDA). These datasheets are fully integrated within the monitoring software's to help users assessing properly each indicator.

Table 4 Datasheet - Indicator C4.1 Degree of prevention of light emissions

\begin{tabular}{|c|c|}
\hline Definition & $\begin{array}{l}\text { Level of measures put in place in order to prevent useless light emissions during the night while } \\
\text { respecting security standards. }\end{array}$ \\
\hline Evaluation method & Qualitative analysis of the project lighting plan. \\
\hline VL (limit value) & $\begin{array}{l}\text { The lighting of the project is limited to the minimum legal requirements in terms of prevention } \\
\text { [36]. }\end{array}$ \\
\hline$V_{A}$ (average value) & $\begin{array}{l}\text { The lighting of the project is integrated into a global lighting plan, which meets the legal } \\
\text { requirements in terms of prevention. }\end{array}$ \\
\hline$V_{B}$ («best practice» value) & $\begin{array}{l}\text { The lighting of the project is integrated into a global lighting plan, which meets the legal } \\
\text { requirements in terms of prevention and imposes authorizations and schedules for private and } \\
\text { public lighting (façades, commercial advertisement, etc.). }\end{array}$ \\
\hline Data sources & Plans and data of the project, lighting plan description. \\
\hline Reference & {$[36,37]$} \\
\hline
\end{tabular}

Table 5 Datasheet - Indicator P5.3 Spatial daylight autonomy (sDA).

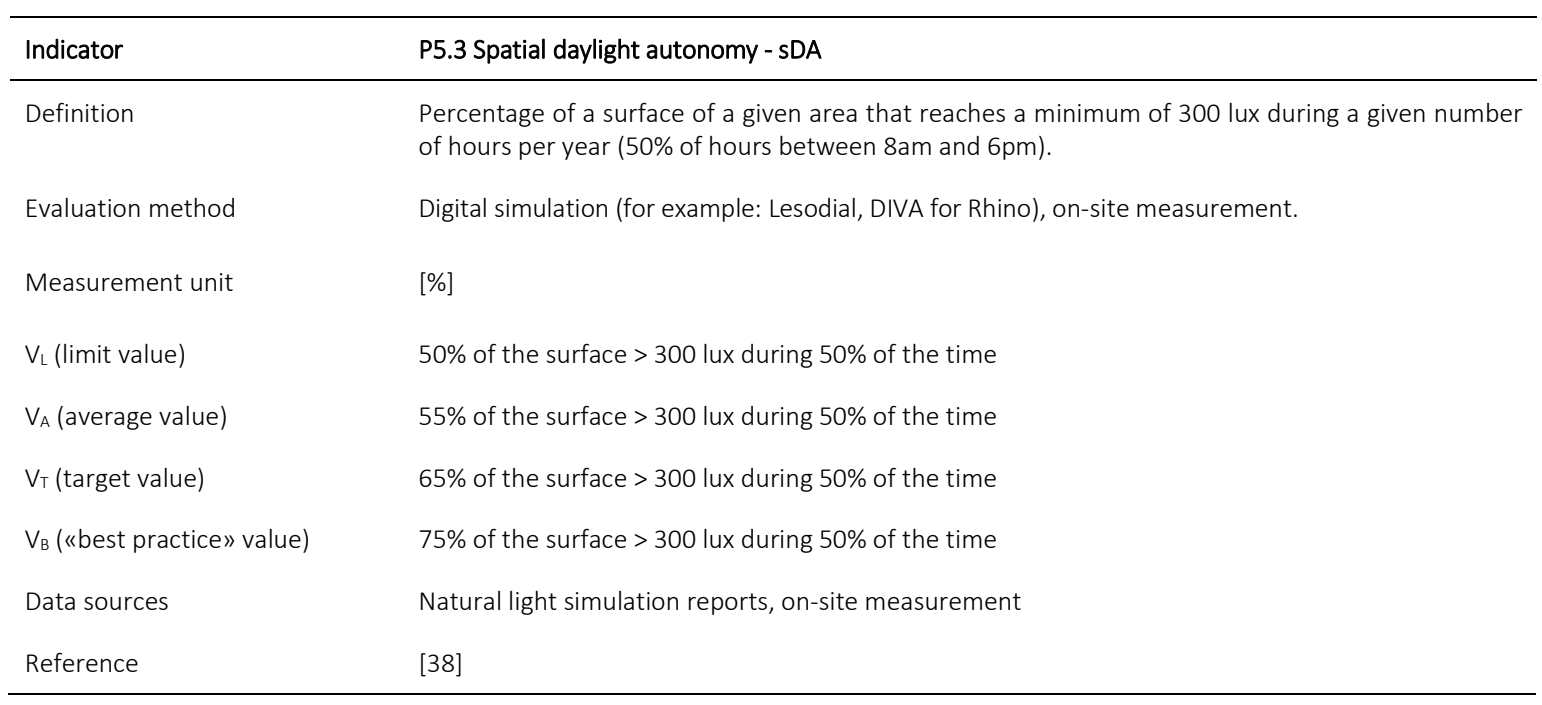




\subsection{Features of the monitoring software}

Originally, OKpilot is a web-based solution designed to help businesses and organizations comply with different frameworks or checklists (sustainability, quality, social responsibility, occupational safety, and health, etc.) and increase their performances. The monitoring software has assessments, management, and results reporting features that allow an optimal control of projects and activities. In this sense, it is divided into three main interrelated sections: Assessment, Outputs, and Management. The principal advantage of OKpilot is its adaptability thanks to a clear dissociation between its monitoring functionalities and the assessment database. Following some adjustments, OKpilot supports efficiently the indicator system SIPRIUS.

Figure 2 shows the Assessment section of the tool. A customized slider allows assessing the performance (VL, $V A, V T$, and $V B$ ) for each indicator. A description of each reference value is available in the assessment module along with a description of the indicator and references. It corresponds to the digitalized version of the datasheets. A standard color code is associated to each reference value: orange corresponds to VL, yellow to VA, light green to VC and dark green to VB. As for red, it corresponds to an indicator whose performance does not reach the limit value $(V L)$.

\section{Criteria > C4 Light Pollution > Indicator C4.1 Degree of prevention of light emission}

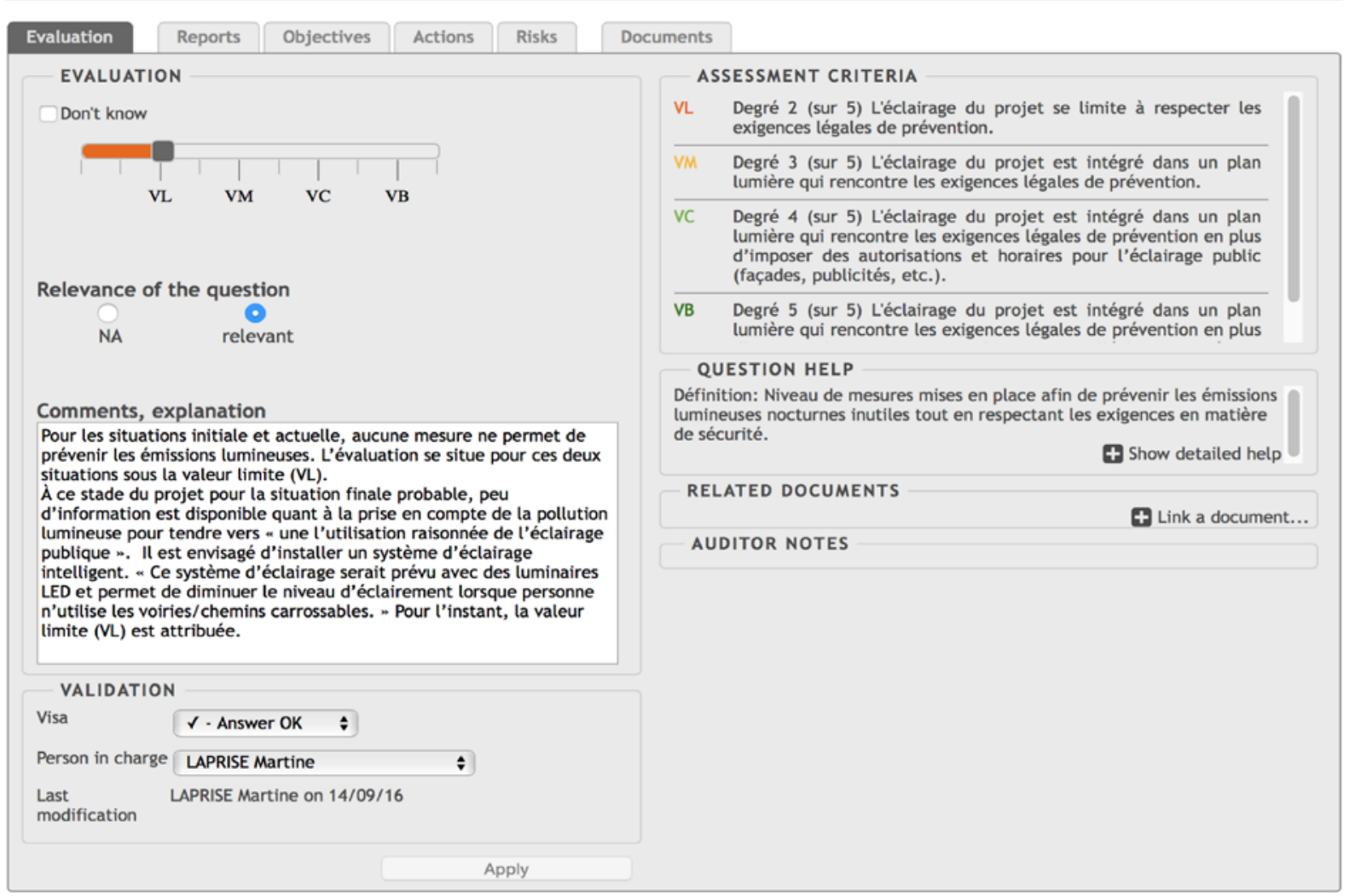

Figure 2 Screenshot of the assessment module of SIPRIUS+ in the Assessment section

The Outcomes section of the monitoring tool offers different graphical displays of the results. They can be seen in Figure 5, Figure 6, and Figure 7 as the results of the test-applications in Chapter 3. The Evolution display (Figure 5; Chapter 4) is a completely new feature of the monitoring tool. It shows the evolution of a given indicator from the Initial objective, or Initial situation, to the Expected Final situation, including as well the 
Current situation. The Chart display (Figure 6; Chapter 4) is used to show an overview of the global results of an assessment by category of criteria (Context, Project or Governance). It shows all assessed indicators simultaneously. Options were added to customize the visualization according to a selection of indicators or sustainability aspects. The Repartition display (Figure 7; Chapter 4) condenses several indicators according to their performance.

The Management section originally included in OKpilot has useful monitoring features (risk alerts, objective setting, deadlines, internal mail, users profile, etc.) that are highly functional and strongly compatible with the sustainability monitoring of a UBRP.

Using computer language, SIPRIUS+ is more precisely a SaaS (System as a Service), that is to say that it is accessible online simultaneously via different individual logins and passwords. It is accordingly a collaborative monitoring tool. As an introduction to the next chapter, Figure 3 shows the customizable home screen designed for SIPRIUS+, including a simplified menu.
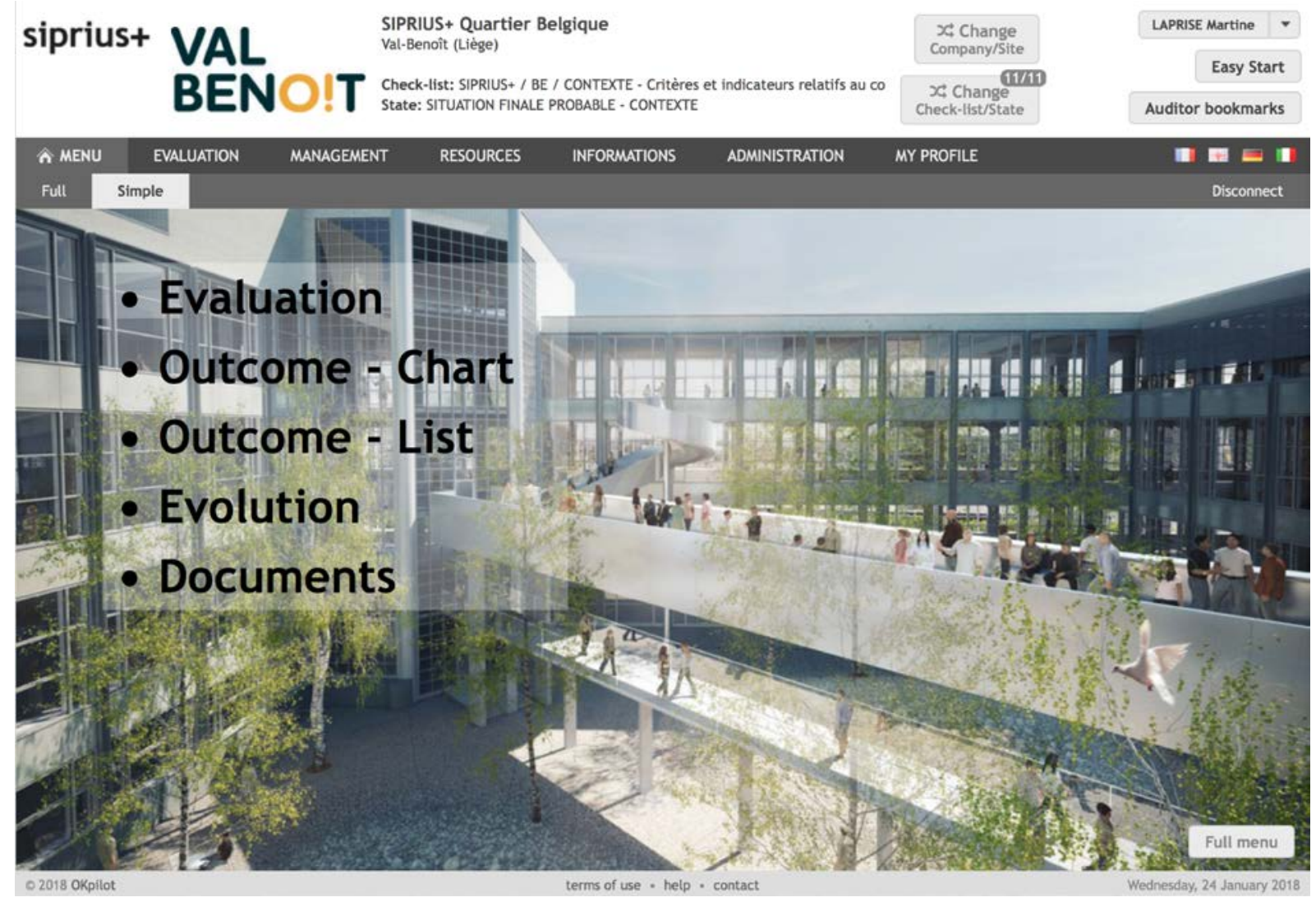

Figure 3 SIPRIUS+ Home screen customized for the Val Benoit case study.

\section{Test-application}

We now have in hand an operational monitoring tool which intends to facilitate the transformation of urban brownfields into sustainable neighborhoods. Essentially, the goal of the test-applications is to check compliance of the tool with the three general requirements. In the same time, this first step is also a means to verify the robustness and functioning of SIPRIUS+, looking at the assessment features and the clarity of the results. While it 
brings interesting information about the sustainability performances of a UBRP, we will not give projects recommendation or compare them, as it is not the purpose of this verification process.

The test-applications were performed by the research team of SIPRIUS+ on three case studies: 1) the Gare-Lac neighborhood in Yverdon-les-Bains (Switzerland), an industrial brownfield of 23 hectares; 2) the Pôle Viotte in Besançon (France), a railway brownfield site of 11 hectares, and 3) the Val Benoit project in Liège (Belgium), an institutional brownfield of 8 hectares. These projects underway were chosen for their representativeness of UBRP and for their strong determination to integrate holistic sustainability objectives. At the moment of the test-applications, none of them were performing sustainability monitoring.

For the purpose of the test-applications, all indicators were assessed with SIPRIUS+, including those that were not subject to a particular attention by the case studies. As an example, we present here the Val Benoit project starting with a description of the case study. Then, we show the assessment results of 3 different indicators as well as the global results of the test-application. Finally, we give a synthesis of this first verification phase with the results of the three case studies.

\subsection{Case study: The Val Benoit project}

The Val Benoit project is located on the former campus of the University of Liège, which abandoned in 2006 its modern buildings built in the 1930s. As a typical brownfield, the site is disconnected from its surrounding to the North by the motorway links, to the East by the Meuse river, to the South by an industrial zone and to the West by a railway. This insular aspect is exacerbated by the topography of the site: access to the buildings is 2 meters lower than the perimeter of the brownfield site. Yet, the site is close to the Guillemin TGV and railway station $(1000 \mathrm{~m})$, what makes it well connected regarding mobility. Initiated in 2007, the Master Plan, developed by a multidisciplinary team, was officially adopted in 2013 [39] (see Figure 4). It consists of a mixed-use neighborhood (400 inhabitants +340 jobs) with new and renovated buildings that put emphasis on the quality of life thanks to green and public spaces, soft mobility networks, eco-friendly construction and good access to services. At the moment of the test-application, the Genie Civil Building (Figure 4, number 1) was under construction.

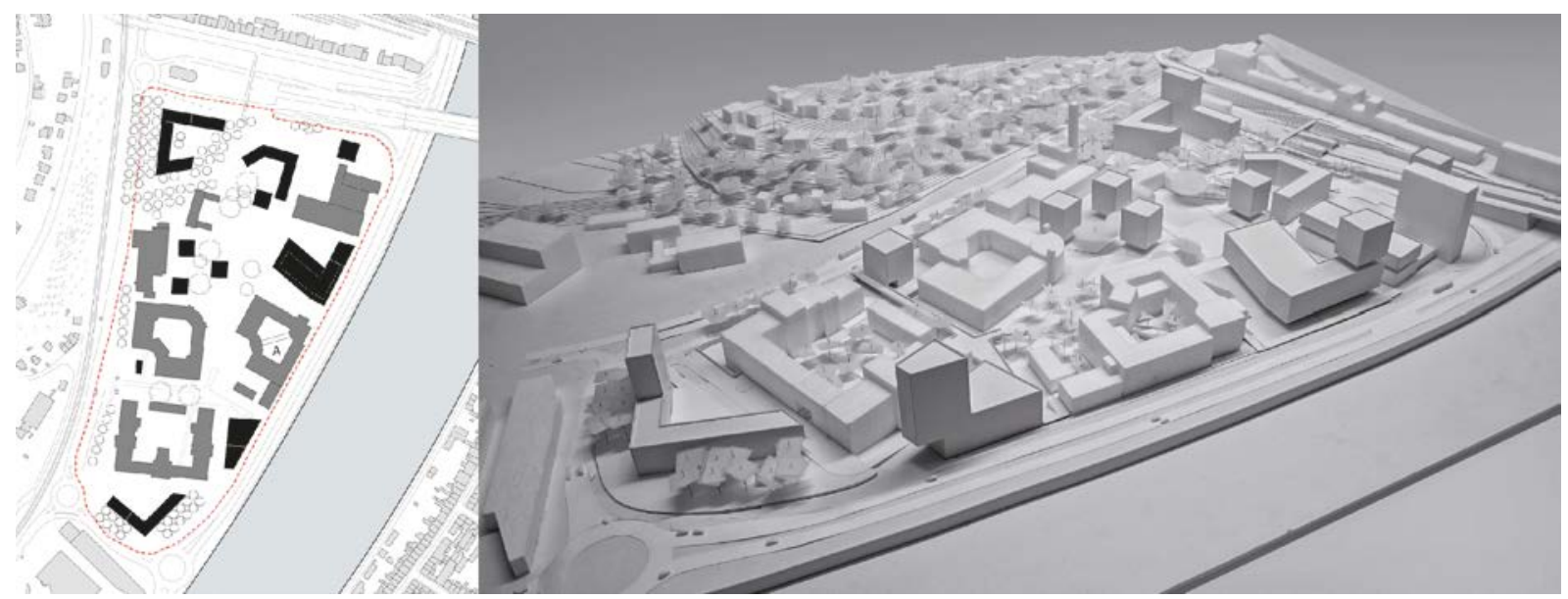

Figure 4 (Left) Masterplan of the Val Benoit Project in Liège (Belgium). In grey, existing buildings to be retrofitted, in black future buildings. (Right) Model of the Val Benoit Project [39]. 


\subsection{Assessment of context, project and governance indicators}

When using SIPRIUS+, sustainability assessment is performed in the perspective of long-term follow up of the performance of each indicator. In other words, to monitor sustainability. In this sense, for the context indicators, we assess the Initial situation (before the project was initiated), the Actual situation and the Expected Final situation. For the project indicators, we assess the Initial objectives (Master plan), the Actual situation in detail (the operational phase, the execution phase and the design phase of the project) and the Expected Final situation. Finally, for the governance indicators, we assess the Initial objectives (Master plan), the Actual situation and the Expected Final situation.

Figure 6 gives an example of the assessment results of a Context, a Project and a Governance indicator using the Evolution display of SIPRIUS+. If we itemize the context indicator C4.1 Degree of prevention of light emissions, we notice that the Initial situation and the Current situation are evaluated "red", i.e. under the Limit Value $\left(V_{L}\right)$. This is explained by the fact that there is no consideration of this issue within the perimeter of the site for these two situations. However, the Master Plan for the new neighborhood includes some measures to prevent light pollution such as a sparing use of public lighting or the installation of presence sensors. Given this information, the C4.1 indicator equals the Limit Value $\left(V_{L}\right)$ for the Expected Final situation.

\section{C4.1 light emissions [qual.]}

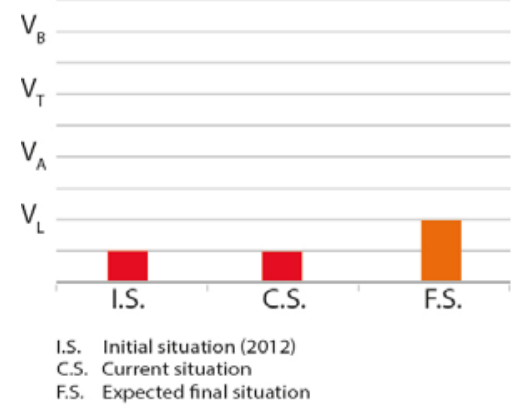

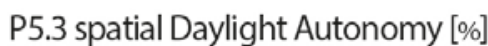

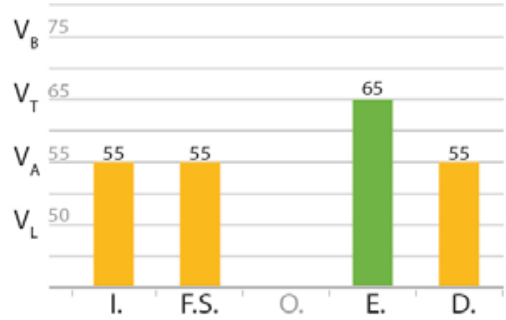

I. Initial objectives (Master plan)

F.S. Expected final situation

O. Operational phase

E. Execution phase-not assessed

D. Design phase
G2.1 temporary uses [qual.]

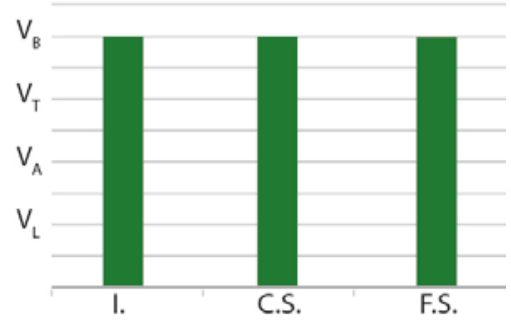

I. Initial objective (Master plan)

C.S. Current situation

F.S. Expected final situation

Figure 5 Evolution display of a Context, Project and Governance indicator.

Figure 6 shows the global result of the test-application using the Chart display, which reveals the sustainability performances of a given situation. We selected here the Expected Final situation, that is to say, the values we can anticipate for each indicator at the end of the project based on all elements known at the time of the assessment. This way of looking at the results is interesting as it gives a comprehensive portrait and a shared vision of where the project is heading in terms of sustainability objectives. Finally, Figure 7 is a summary of the repartition of the indicators according to their performance. This display is more of an introduction to the results, because less transparent. It can be used eventually to compare rapidly different options of a UBRP. It is worth noting that all the results are dynamic and will change along with the evolution of the project. 
SIPRIUS+ Val Benoit project

Expected Final Situation (C, P and G)

C1.1 Quality of public transport

C1.2 Nbr of parking spaces

C1.3 Soft mobility network

C1.4 Company mobility plan

$\mathrm{C} 2.1 \mathrm{NO}_{2}$ emission

C3.1 Noise - day

C3.2 Noise - night

C4.1 Prevention of light emission

C5.1 Distance nursery

C5.2 Distance kindergarten

C5.3 Distance elementary school

C5.4 Distance middle school

C5.5 Distance high school

C6.1 Distance commercial zone

C7.1 Distance public park

C7.2 Distance green/natural area

C7.3 Distance cultural center

C7.4 Distance sport center

C8.1 Population density

C9.1 Employment density

C10.1 Local companies

P1.1 Land use coefficient

P2.2 Energies buildings operation

P3.1 Infiltration stormwater

P4.1 Green surfaces

P4.2 Ecosystems

P5.1 Overheating

P5.2 Noise - indoor

P5.3 Spatial daylight autonomy

P5.5 Individualization of housing

P5.6 Outdoor spaces

P6.1 Degree of security

P7.1 Existing heritage

P8.1 Functional mix

P8.2 Social mix

P8.3 Universal access

P9.1 Investment costs

P9.2 Gross rental yield

P10.1 Operating costs

P10.2 Level of occupancy

P12.1 Buildings flexibility

G1.1 Project footprint

G1.2 Site remediation

G2.1 Temporary use

G3.1 Construction waste

G3.2 Construction disturbance

G4.1 Commissioning

G5.1 Population participation

G6.1 Professional collaboration

G7.1 Information access

G8.1 Evaluation process
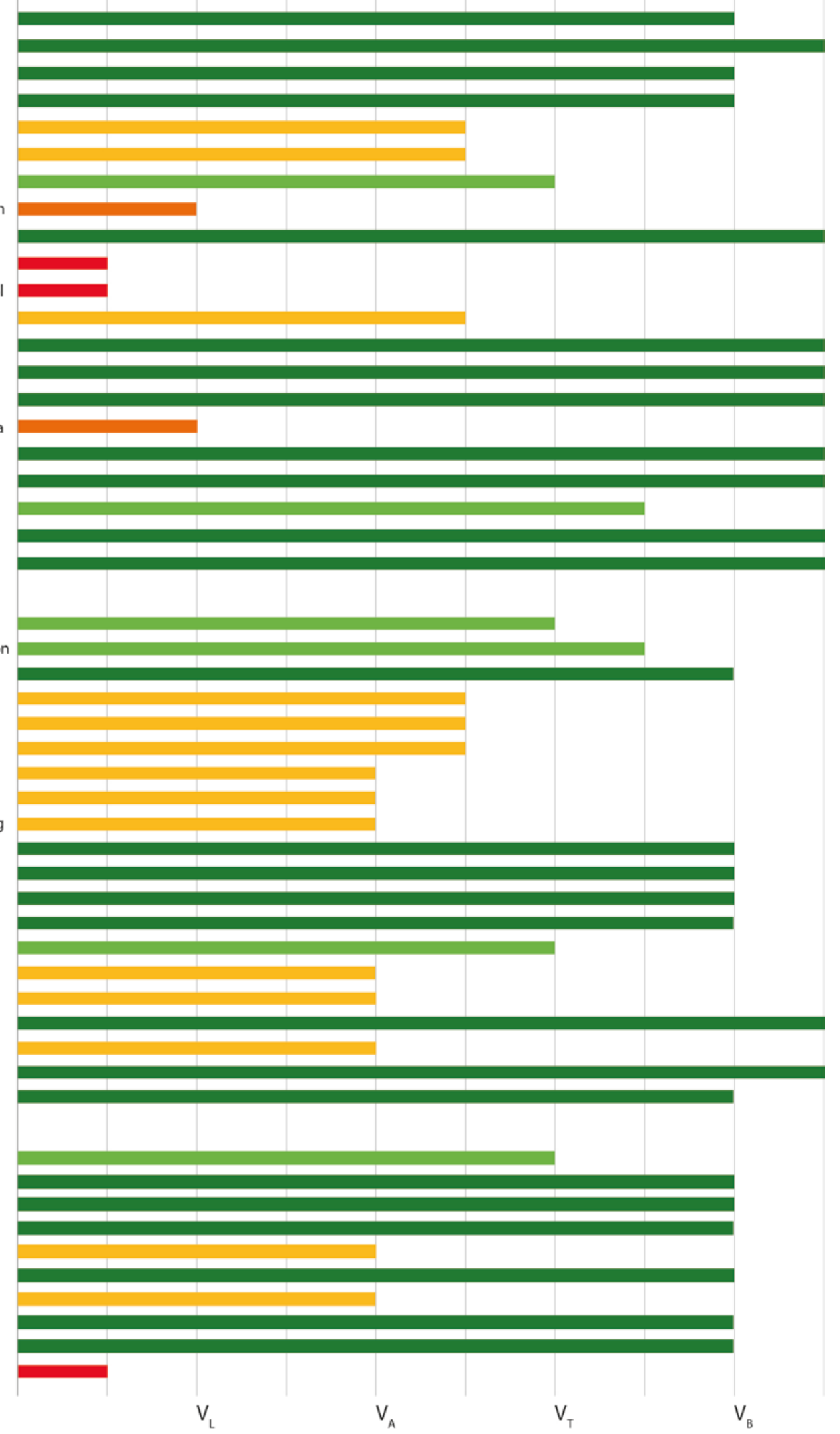

Figure 6 Global results of the test-application for the Expect Final situation 


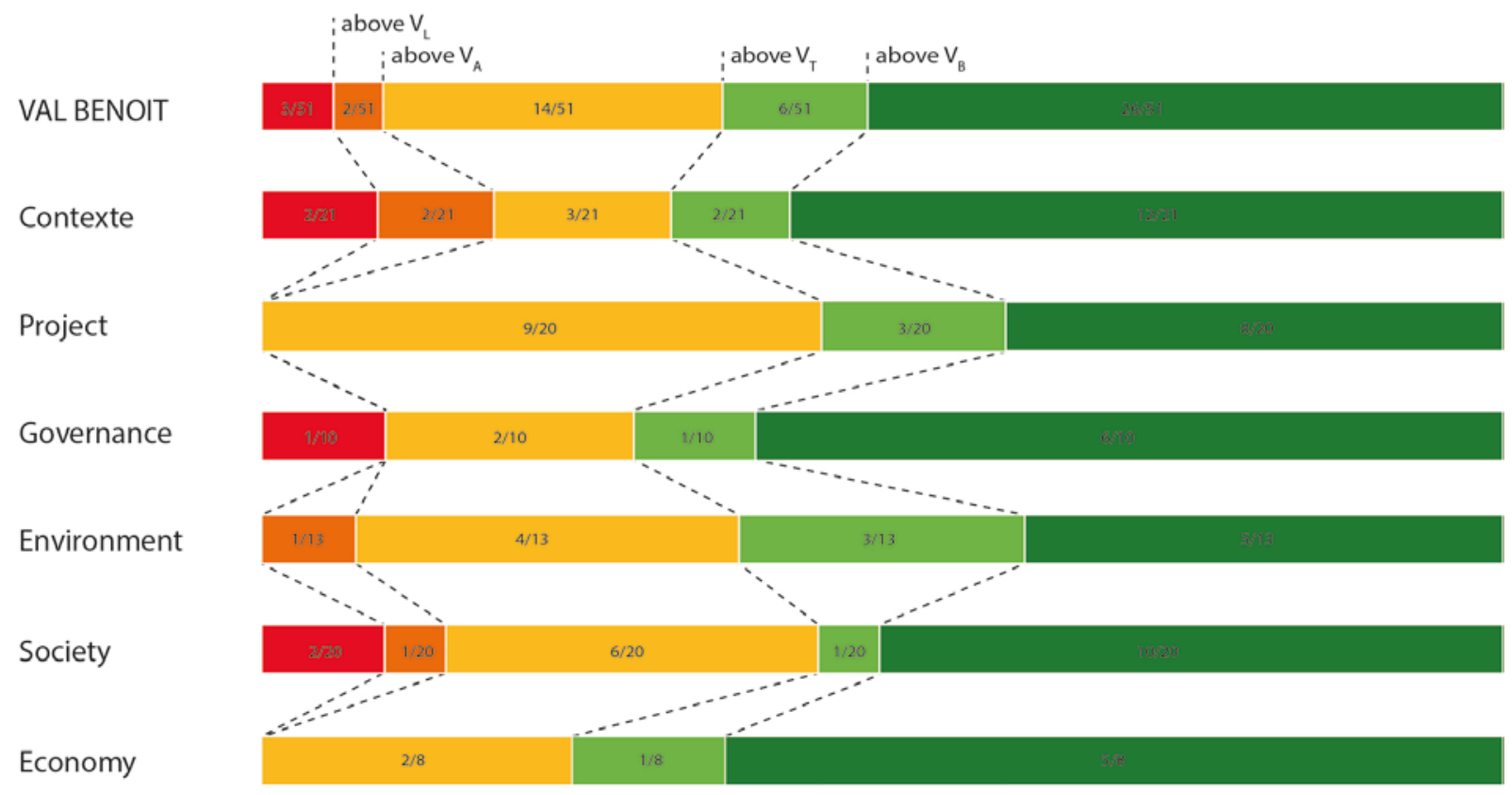

Figure 7 Repartition display of the indicators according to their performance for the Expect Final situation

\subsection{Results of the test-applications}

The three test-applications were conducted to check the performances of SIPRIUS+ as an operational monitoring tool that includes a search for global quality, that is specific to UBRP and that is integrated into the project dynamics. They served as well to make some fine-tuning of the tool.

The results of the test-applications on the three case studies were overall similar (for complete results, see [40]). They validate the relevance of Context, Project and Governance indicators and their reference values in each country. Consequently, it confirms that SIPRIUS+ covers equally the three pillars of sustainability (attribute 1) and includes as well the "fourth pillar" of sustainability (attribute 2). In addition, we notice that the sustainability issues raised by the indicators are significant to the specificities of urban brownfields (attribute 3). As a first application on the case studies, mostly assessing the Master Plans of the three projects, we can add that SIPRIUS+ is appropriate for ex ante assessment (attribute 5). As such, the sustainability assessment allows stakeholders involved in UBRP to verify and set sustainability objectives. All these considerations are expressed in Table 6.

Nevertheless, as it can be seen in Table 6, some attributes could not be sufficiently verified with the testapplications. At this stage, we only know that SIPRIUS+ has the potential to meet them. These attributes $(4,6,7$, and 8) are directly linked to the long-term sustainability monitoring of UBRP. Because these projects can last over a decade, doing regular test-applications of the monitoring tool on a long-term period including a multidisciplinary participation was not feasible in the framework of this work. For this reason, a second stage is included in this verification process of the research project. 
Table 6 Results of the first verification stage: compliance with the eight attributes.

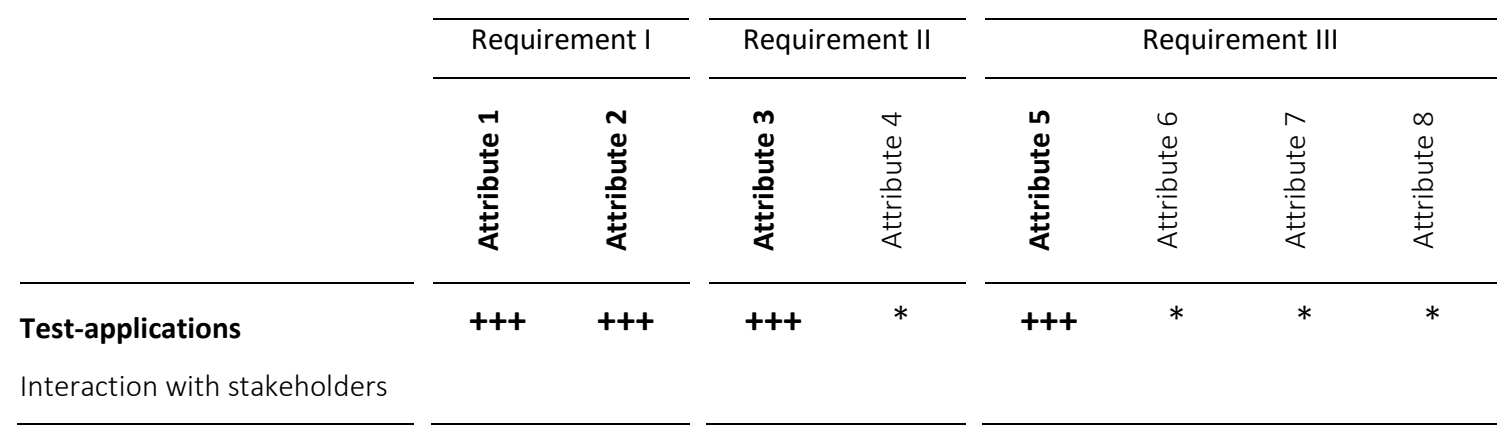

$(+++)$ consistent $\quad(++)$ partly consistent $\quad(+)$ very partly consistent $\quad(*)$ needs complementary verification

\section{Interaction with stakeholders}

The second verification stage is meant to complete the test-applications by confronting the tool and its results to the stakeholders involved in the case studies. In this sense, it will question more precisely their perception on the attributes related to the practice of sustainability monitoring. The interactions took the form of roundtables organized for each case study. When conducting roundtable sessions, it is suggested to establish a range of topics to guide the discussion [41]. Hence, the topics addressed concern the potential of SIPRIUS+ to foster:

- The in itinere and ex-post follow-up of the sustainability objectives of the UBRP (Attributes 6 and 7);

- The communication of the sustainability objectives of the UBRP with a multidisciplinary audience (Attribute 4);

- The improvement and optimization of the sustainability objectives of the UBRP (Attribute 8).

Before opening the roundtable discussions, detailed information about SIPRIUS+ is given. First, the research team makes an online presentation of SIPRIUS+. This presentation is personalized for each case study as it shows the test-application made during the first verification stage. Therefore, stakeholders are not only able to see the diverse functionalities of the monitoring tool, but also a dynamic overview of the performances of their UBRP. Next, an evaluation report is given to each participant of the three case studies. Directly extracted from SIPRIUS+, the evaluation report gives detailed information about over 50 sustainability indicators. As such, it is a major output of the monitoring tool. Finally, the research team moderates the discussion, according to the topics previously defined. It is important to underline that these roundtables serve as a complementary verification of the test-applications. They are not a foolproof demonstration of the tool and neither claim to bring statistical outputs.

\subsection{Results of the interactions with the stakeholders}

In total, 15 participants from different disciplines (architecture, urbanism, engineering, project management, and politics) have taken part in the three roundtables (see Figure 8 for example). The discussions reported here highlight in a qualitative way the trends and the perceptions about SIPRIUS+; more specifically, the performance of its monitoring features and, in a general way, its potential to answer the three requirements. 

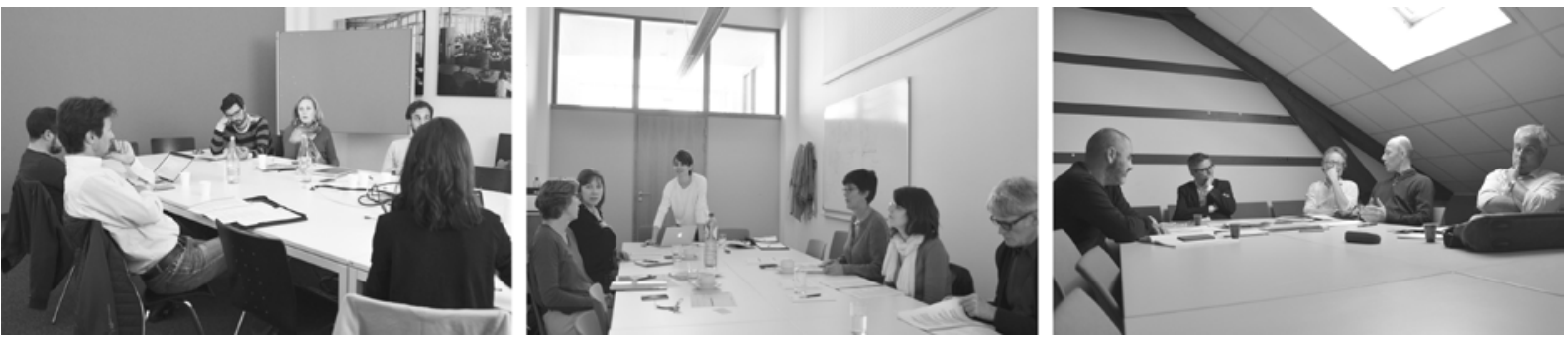

Figure 8 Interactions with the stakeholders in Switzerland, Belgium, and France.

First, the stakeholders agreed on the fact that SIPRIUS+ could contribute maintaining the sustainability objectives over the long term of UBRP. In that respect, the word "dashboard" has been associated with SIPRIUS+ several times, showing the perception of the potential users regarding the support the tool can bring. Following this idea, it was also said that the tool could provide the basis for planning and for acting in a timely manner on the sustainability performances at the neighborhood scale. In that sense, SIPRIUS+ has the potential to foster in itinere and ex-post follow-up (attributes 6 and 7). Second, the majority of the stakeholders agreed on the fact that SIPRIUS+ could be a relevant tool to build a shared vision of the sustainability of their UBRP. In that order, it could facilitate the communication about this vision within the internal and external teams of the project, which are usually multidisciplinary (attribute 4). It could also facilitate the communication with a broader audience, such as the population. However, divergences appeared among stakeholders about the level of information to communicate to the public. We believe that this latter concern is part of the internal logic of each project, although SIPRIUS+ could be used for this purpose. Finally, stakeholders agreed on the fact that the monitoring provided by SIPRIUS+ could stimulate an iterative process, that is to say, a willingness to improve and optimize sustainability parameters of their project (attribute 8). It was interesting to observe how all the participants felt involved with the results of the test-applications and their desire to improve indicators with a low performance and turn them "green". Table 7 shows how the stakeholders recognized, through the topics discussed, the potential of SIPRIUS+ to give the means to transform their urban brownfield in more ecologically friendly, socially inclusive neighborhoods, mindful of the welfare of future generation.

Table 7 Results of the second verification stage: compliance with the eight attributes.

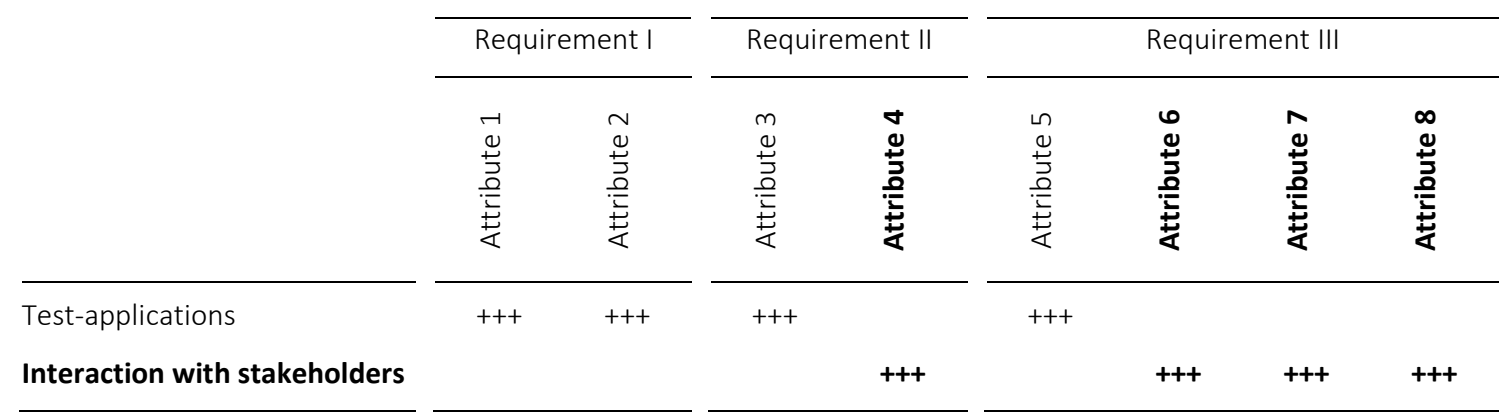

$(+++)$ consistent $\quad(++)$ partly consistent $\quad(+)$ very partly consistent $\quad(*)$ needs complementary verification 


\section{Discussion}

By definition, sustainability monitoring consists of a regular and structured follow-up of a number of specific indicators. Because UBRP are complex operations lasting over a decade, testing the tool on this long-term period is not conceivable in the framework of this research. Instead, the verification stage focused on the capacity of the tool to meet three general requirements: (I) a search for global quality; (II) an adequacy with the specificities of UBRP; (III) an integration into the project dynamics [24]. They were divided into attributes to allow a finer analysis of the two complementary tests. Overall, the test-applications and interactions with stakeholders gave positive results, showing a consistency of SIPRIUS + with the eight attributes, and by extension the three general requirements. In that sense, they validate the hybridization strategy used for the making of the tool (Chapter 2). Although the two complementary tests are not an absolute and definitive confirmation of the efficiency of the tool, they underline the potential of SIPRIUS+ to facilitate the transformation of urban brownfields into sustainable neighborhoods. We discuss here the results from this angle.

\subsection{Relevance of the operational monitoring tool}

The test-applications can be appreciated through the different graphical displays, which lead to a number of observations. Looking at Figure 7, we notice a high performance for the Val Benoit project: 32 indicators out of 51 are rated "green" (above the Target Value - $\mathrm{V}_{T}$ ). We can notice the same high performances for the Gare-Lac neighborhood (Switzerland) and the Pôle Viotte (France) where respectively 34 out of 52 indicators and 30 out of 51 indicators are above the Target Value - $\mathrm{V}_{\mathrm{T}}$. This is explained on the one hand by the fact that the projects were chosen for their willingness to integrated sustainability issues in a holistic way and, on the other hand, because all case studies are at the beginning of their process. Hence, monitoring sustainability appears of foremost importance to pursue these objectives throughout the project and to eventually improve indicators that are less performing.

Thanks to the Chart display, SIPRIUS+ allows comparing the Expected Final situation (Figure 6) with the Initial Situation, Objectives and with the Current Situation. In a monitoring perspective involving a continuous improvement of sustainability objectives, some points are worth noting for the stakeholders involved in the UBRP. First, the indicators in "red" that do not reach the Limit Value $\left(V_{L}\right)$ need a special attention since, for most of them, it is a veto value according to the current and contextualized regulation. A "red" result can also be the sign that a sustainability aspect was forgotten in the formulation of the UBRP. In this way, SIPRIUS+ acts as a checklist. Second, attention should be put on the indicators with a lower performance for the Expected Final situation than for the other situations. Ideally, the new neighborhood must improve the conditions of the brownfield site and not the opposite. Finally, stakeholders can decide to put their attention on less performing indicators and address the challenge of improving them.

The Evolution display of SIPRIUS+ alone reflects the principles of monitoring (see Figure 5). It gives a way to look at the results in detail and to understand the development of a given indicator according to the evolution of the UBRP. It is worth noting that this display comes with comments or explanations (see Figure 2) in order to keep 
track of the parameters taken into consideration at the moment of the assessment. Hence, the use of SIPRIUS+ relies on multidisciplinary inputs.

The interactions with the stakeholders of the tree case studies were the occasion to gather insightful information about their perception of the usability of the tool in daily practice. First, even if it is conceived as a collaborative and multidisciplinary tool, the stakeholders agreed on the fact that someone should lead the monitoring process of the UBRP, in this case using SIPRIUS+. They have identified the project manager as being the most appropriate to be this pilot. Interestingly, the project managers of the three case study took part in these interactions. Second, a discussion about the frequency of use of SIPRIUS+ revealed that a periodical assessment, coinciding for instance with the annual review of the project, would be appropriate. In parallel, complementary strategic assessments could be performed according to the evolution of the UBRP (modification of the project, construction of a building, etc.).

Finally, the cost of the tool, which would consist of a yearly subscription and depend on the number of users, was not considered as an obstacle when compared to the magnitude of a UBRP. It is mostly organizational obstacles that were identified. Indeed, including the practice of monitoring requires time and investment. However, the stakeholders have recognized that long-term sustainability monitoring could improve the global quality of the future neighborhood and, by consequence, benefit post-occupancy (maintenance, acceptance, consumption costs, indirect costs, etc.). Generally speaking, what emerges from these interactions is that, whereas the use of such a tool implies a change in the management of these projects, the evolutions to adopt in order to include this practice appear not only feasible, but also realistic and desired.

\subsection{Limits of the verification stage}

Within the scope of this verification stage, we notice some limitations of the test-applications and the interactions with the stakeholders of the three case studies. The test-applications revealed that assessment at an early stage, which is the case for the three case studies, implies a certain number of estimation since all required data are not always already available. This is particularly true for well-being and economic indicators. Monitoring principles involving a regular follow-up of sustainability objectives allow adjustment, which should provide more accurate assessment according to the project progress. In any case, assessment results should be regarded as work instrument and not static data. In other words, as an indication of how the future neighborhood is dealing with sustainability objectives in order to adjust the project accordingly.

For the interaction with the stakeholders, a questionnaire targeting their perception of the tool was initially provided. However, the number of stakeholders taking part in the roundtables was limited to fifteen. According to statistical methods, this is not enough to articulate quantitative conclusions on the level of perception on given aspects. This said, the roundtables remain relevant to disclose underlying trends about the perception of SIPRIUS+.

Finally, the test-applications were performed by the research team and, consequently, end-users have not directly used the tool during this verification stage. This situation can have an influence on the interactions with 
the stakeholders as the discussions can be disembodied from the practice. We know that the monitoring software at the base of SIPRIUS+ (cf. Chapter 2) is already used by hundreds of companies in Europe that consolidate its functioning. Nevertheless, a utilization phase involving the stakeholders of the case studies could contribute to corroborate the results of both application-tests and roundtables.

\section{Conclusion}

UBRP are not automatically sustainable and have a tendency to change over time. Having a clear idea of where the project is heading in terms of sustainability is crucial to build solid foundation for its future [42]. In this sense, a tailored-made operational monitoring tool appears to be a suitable approach to overcome the complexity of this type of operations and facilitate their transformation into sustainable neighborhoods. This operational monitoring tool must satisfy: (I) a search for global quality; (II) an adequacy with the specificities of UBRP; (III) an integration into the project dynamics. Following these considerations, this research project has developed SIPRIUS+, which is a hybrid between a multicriteria indicator system and a monitoring software.

Despite some limitations, the test-applications of SIPRIUS+ on case studies in Belgium, France, and Switzerland and the interactions with the involved stakeholders have shown compliance with the three general requirements. It has also proven its potential added value to meet the objective: facilitating the transformation of urban brownfields into sustainable neighborhoods. It can provide useful information to integrate and pursue sustainability objectives throughout the regeneration process thanks to global and detailed assessment results. In other words, SIPRIUS+ gives a shared vision of the sustainability objectives of the future neighborhood. In this sense, the operational monitoring tool is expected to contribute to decision-making in a multidisciplinary manner, without ever giving ready-made solutions, but allowing iterative settings of the project. The concretization of the sustainability vision and maintaining of the objectives will always depend on the motivation and involvement of the stakeholders. This research has shown that the inclusion of a monitoring practice is not only feasible but also realistic and desired. Current works involve updates of the indicators and continuous improvement of the tool. Future experimentations of the tool will be done through an implementation phase in one of the case studies, which will lead to further publications.

\section{Acknowledgements}

We would like to acknowledge financial support from Swiss National Science Foundation within the framework of Project No 100013_143376. We thank the stakeholders of the three case studies who have participated in the roundtables and shared the data for the test-applications, in particular Fabienne Hennequin, Charlotte Malignac and Olivier Govignaux. We also thank Emily Nault and Sergi Aguacil for their support in the calculation of several indicators.

\section{References}

[1] EEA, OPOCE, Urban sprawl in Europe. The ignored challenge, EEA (european environment agency), Copenhagen, 2006. http://www.eea.europa.eu/publications/eea_report_2006_10. 
[2] C. Couch, L. Leontidou, G. Petschel-Held, eds., Urban Sprawl in Europe: Landscapes, Land-Use Change and Policy, Blackwell Publishing, Oxford, 2007. http://www.rudi.net/node/20728 (accessed February 21, 2014).

[3] E. Rey (Ed.), Green density, Presses Polytechniques et Universitaires Romandes, Lausanne, 2013.

[4] M. Jenks, The compact city: a sustainable urban form?, [Reprinted], Spon, London etc, 1998.

[5] R. Rogers, P. Gumuchdjian, Cities for a small planet, Icon Editions, Westview, Boulder, Colo., 1998.

[6] CABERNET, Sustainable Brownfield Regeneration: CABERNET Network Report, (2006).

[7] G. Thornton, M. Franz, D. Edwards, G. Pahlen, P. Nathanail, The challenge of sustainability: incentives for brownfield regeneration in Europe, Environmental Science \& Policy. 10 (2007) 116-134. doi:10.1016/j.envsci.2006.08.008.

[8] A. Schulze Bäing, C. Wong, Brownfield Residential Development: What Happens to the Most Deprived Neighbourhoods in England?, Urban Studies. 49 (2012) 2989-3008. doi:10.1177/0042098012439108.

[9] G.T. Rowan, C. Fridgen, Brownfields and Environmental Justice: The Threats and Challenges of Contamination, Environmental Practice. null (2003) 58-61. doi:10.1017/S1466046603030163.

[10] J. Mathey, S. RöBler, J. Banse, I. Lehmann, A. Bräuer, Brownfields As an Element of Green Infrastructure for Implementing Ecosystem Services into Urban Areas, Journal of Urban Planning and Development. 0 (2015) A4015001. doi:10.1061/(ASCE)UP.1943-5444.0000275.

[11] J.I. Gilderbloom, W.L. Meares, W. Riggs, How brownfield sites kill places and people: an examination of neighborhood housing values, foreclosures, and lifespan, Journal of Urbanism: International Research on Placemaking and Urban Sustainability. 9 (2014) 1-18. doi:10.1080/17549175.2014.905488.

[12] CABERNET, The Need to Consider Social and Cultural Objectives When Regenerating Brownfields in Europe, (2004).

[13] C.A.D. Sousa, Measuring the Public Costs and Benefits of Brownfield versus Greenfield Development in the Greater Toronto Area, Environ Plann B Plann Des. 29 (2002) 251-280. doi:10.1068/b1283.

[14] Z. Kotval-K, Brownfield Redevelopment Why Public Investments Can Pay Off, Economic Development Quarterly. 30 (2016) 275-282. doi:10.1177/0891242416656049.

[15] J.B. Eisen, Brownfield policies for sustainable cities, Duke Environmental Law \& Policy Forum. 9 (1999) 187-229.

[16] T. Dixon, Integrating Sustainability into Brownfield Regeneration: Rhetoric or Reality? - An Analysis of the UK Development Industry, Journal of Property Research. 23 (2006) 237-267. doi:10.1080/09599910600933889.

[17] M. Franz, G. Pahlen, P. Nathanail, N. Okuniek, A. Koj, Sustainable development and brownfield regeneration. What defines the quality of derelict land recycling?, Environmental Sciences. 3 (2006) 135151. doi:10.1080/15693430600800873.

[18] K. Pediaditi, K.J. Doick, A.J. Moffat, Monitoring and evaluation practice for brownfield, regeneration to greenspace initiatives: A meta-evaluation of assessment and monitoring tools, Landscape and Urban Planning. 97 (2010) 22-36. doi:10.1016/j.landurbplan.2010.04.007.

[19] G. Antonio Da Cunha, Enjeux du développement urbain durable : transformations urbaines, gestion des ressources et gouvernance, Presses polytechniques et universitaires romandes, Lausanne, 2005. 
[20] A. Sharifi, A. Murayama, A critical review of seven selected neighborhood sustainability assessment tools, Environmental Impact Assessment Review. 38 (2013) 73-87. doi:10.1016/j.eiar.2012.06.006.

[21] D. Edwards, G. Pahlen, C. Bertram, P. Nathanail, Best Practice Guidance for Sustainable Brownfield Regeneration, (2005).

[22] S. Bartke, R. Schwarze, No perfect tools: Trade-offs of sustainability principles and user requirements in designing support tools for land-use decisions between greenfields and brownfields, Journal of Environmental Management. 153 (2015) 11-24. doi:10.1016/j.jenvman.2015.01.040.

[23] U. Berardi, Beyond Sustainability Assessment Systems: Upgrading Topics by Enlarging The Scale of Assessment, International Journal of Sustainable Building Technology and Urban Development. 2 (2011) 276-282. doi:10.5390/SUSB.2011.2.4.276.

[24] E. Rey, Régénération des friches urbaines et développement durable : vers une évaluation intégrée à la dynamique du projet, Presses Universitaires de Louvain, Louvain-La-Neuve, 2012.

[25] HOMBRE, HOMBRE's Role in Brownfield Management and Avoidance, 2014. www.zerobrownfield.eu.

[26] L. Pizzol, A. Zabeo, P. Klusáček, E. Giubilato, A. Critto, B. Frantál, S. Martinát, J. Kunc, R. Osman, S. Bartke, Timbre Brownfield Prioritization Tool to support effective brownfield regeneration, Journal of Environmental Management. 166 (2016) 178-192. doi:10.1016/j.jenvman.2015.09.030.

[27] M. Laprise, S. Lufkin, E. Rey, An indicator system for the assessment of sustainability integrated into the project dynamics of regeneration of disused urban areas, Building and Environment. 86 (2015) 29-38. doi:10.1016/j.buildenv.2014.12.002.

[28] M. Morio, S. Schädler, M. Finkel, Applying a multi-criteria genetic algorithm framework for brownfield reuse optimization: Improving redevelopment options based on stakeholder preferences, Journal of Environmental Management. 130 (2013) 331-346. doi:10.1016/j.jenvman.2013.09.002.

[29] K.E. Pediaditi, W. Wehrmeyer, J. Chenoweth, Monitoring the Sustainability of Brownfield Redevelopment Projects: The Redevelopment Assessment Framework (RAF), Contaminated Land \& Reclamation. 13 (2005) 173-183. doi:theses/171.

[30] G.C. Wedding, D. Crawford-Brown, Measuring site-level success in brownfield redevelopments: A focus on sustainability and green building, Journal of Environmental Management. 85 (2007) 483-495. doi:10.1016/j.jenvman.2006.10.018.

[31] K. Williams, C. Dair, A framework for assessing the sustainability of brownfield developments, Journal of Environmental Planning and Management. 50 (2007) 23-40. doi:10.1080/09640560601048275.

[32] M. Laprise, S. Lufkin, E. Rey, SIPRIUS+: A sustainability monitoring tool specifically designed for urban brownfields regeneration projects, in: Proceedings of 33rd PLEA International Conference: Design to Thrive, Network for comfort and energy use in buildings (NCEUB), Edinburgh, 2017.

[33] GLOBALITE Management, OKpilot - Solution, (2014). http://okpilot.com/okp_fr/Solution.html (accessed November 2, 2014).

[34] E.K. Zavadskas, K. Govindan, J. Antucheviciene, Z. Turskis, Hybrid multiple criteria decision-making methods: a review of applications for sustainability issues, Economic Research-Ekonomska Istraživanja. 29 (2016) 857-887. doi:10.1080/1331677X.2016.1237302. 
[35] td-net, Swiss Academies of Arts and Sciences, Transdisciplinary research for what?, Network for Transdisciplinary Research. (2017). http://www.transdisciplinarity.ch/en/tdnet/Transdisziplinaritaet/Forschungszwecke.html (accessed September 21, 2017).

[36] SIA, Prévention des émissions inutiles de lumière à l'extérieur, SIA, Zurich, 2013.

[37] FRAPNA, Cahier de recommandation. Eclairage extérieur, Grenoble, 2013.

[38] IES Daylight Metrics Commitee, Approved Method: IES Spatial Daylight Autonomy (sDA) and Annual Sunlight Exposure (ASE), IES Illuminating Engineering Society, New York, 2012.

[39] Baumans-Deffet sprl, Requalification du site du Val Benoit, (2013).

[40] M. Laprise, Monitoring opérationnel pour l'intégration des enjeux de durabilité aux projets de régénération de friches urbaines., Ecole polytechnique fédérale de Lausanne (EPFL), 2017. https://infoscience.epfl.ch/record/232432.

[41] A.N. Oppenheim, Questionnaire design, interviewing and attitude measurement, New edition, Pinter, London, 1992

[42] J.B. Hollander, N. Kirkwood, J.L. Gold, Principles of brownfield regeneration: cleanup, design, and reuse of derelict land, Island Press, Washington, 2010. 